\title{
PENGARUH PENAMBAHAN LIMBAH AMPAS MINUMAN BERKAFEIN SEBAGAI MEDIA TUMBUH HIDROPONIK TERHADAP PERTUMBUHAN TANAMAN SELADA (Lactuca sativa)
}

\author{
THE EFFECT OF ADDING Caffeinated DRINK WASTE AS A HYDROPONIC \\ GROWING MEDIA ON THE GROWTH OF LETTAGE (Lactuca sativa)
}

\author{
Sari Handayani ${ }^{1}$, Marjanah ${ }^{2}$, Ekariana S. Pandia ${ }^{3}$ \\ Prodi Pendidikan Biologi Fakultas Keguruan Dan Ilmu Pendidikan \\ Universitas Samudra \\ Email : Sari62782@gmail.com
}

\begin{abstract}
ABSTRAK
Selada (Lactuca sativa) merupakan salah satu komoditi hortikultura yang memiliki prospek dan nilai komersial yang cukup baik. Penelitian ini bertujuan untuk mengetahui pengaruh penambahan ampas teh dan ampas kopi terhadap pertumbuhan tanaman selada (Lactuca sativa) dan perlakuan manakah yang paling optimum terhadap pertumbuhan tanaman selada (Lactuca sativa) dengan media hidroponik. Metode penelitian eksperimen, dengan Rancangan Acak Lengkap (RAL) yang terdiri dari 4 perlakuan yaitu media tanam hidroponik + air sebagai kontrol (P0), media tanam hidroponik + ampas teh (4gr) + air (P1), media tanam hidroponik + ampas kopi (4gr) + air (P2), media tanam hidroponik + ampas teh (2gr) + ampas kopi (2gr) + air (P3), dengan 6 kali ulangan. Parameter yang diamati berupa pertumbuhan tinggi tanaman (cm/minggu), jumlah daun (helaian/minggu), dan lebar daun $(\mathrm{cm} / \mathrm{minggu})$ tanaman selada (Lactuca sativa). Data dianalisis menggunakan (ANOVA) dengan 5\% dan Uji Kruskal Wallis. Hasil analisis yang diperoleh tidak didapatkannya perbedaan yang nyata pada setiap perlakuan. Data pertumbuhan tinggi tanaman selada diperoleh nilai Asymp. Sig. sebesar 0,206 > 0,05, jumlah helaian daun tanaman selada diperoleh nilai Asymp. Sig. sebesar 0,637 >0,05, dan lebar helaian daun tanaman selada diperoleh nilai $\mathrm{F}$ hitung $<\mathrm{F}$ tabel yaitu $0,45<3,1$ pada taraf $5 \%$. Perlakuan yang paling tinggi untuk tinggi daun $(4,53$ $\mathrm{cm} /$ bulan) dan lebar daun $(1,77 \mathrm{~cm} / \mathrm{bulan})$ tanaman selada yaitu ada perlakuan P1, sedangkan jumlah daun (3,24 helai/bulan) yang paling banyak adalah pada perlakuan P3.
\end{abstract}

Kata kunci: Hidroponik, Limbah Ampas Minuman Berkafein, Pertumbuhan Tanaman Selada (Lactuca sativa).

\section{ABSTRACT}

Lettuce (Lactuca sativa) is a horticultural commodity that has good prospects and commercial value. This study aims to determine the effect of adding tea and coffee grounds on the growth of lettuce (Lactuca sativa) and which treatment is the most optimum for the growth of lettuce (Lactuca sativa) with hydroponic media. Experimental research method, with Completely Randomized Design (CRD) consisting of 4 treatments, namely hydroponic growing media + water as control $(P 0)$, hydroponic growing media + tea dregs $(4 \mathrm{gr})+$ water (P1), hydroponic growing media + coffee grounds $(4 g r)+$ water $(P 2)$, hydroponic growing media + tea dregs $(2 g r)+$ coffee grounds $(2 g r)+$ water $(P 3)$, with 6 replications. Parameters observed were plant height growth (cm/week), number of leaves (strands/week), and leaf width (cm/week) of lettuce (Lactuca sativa). Data were analyzed using (ANOVA) 
with 5\% and Kruskal Wallis Test. The results of the analysis obtained did not find a significant difference in each treatment. Lettuce plant height growth data obtained the Asymp value. Sig. of $0.206>0.05$, the number of lettuce leaves obtained the Asymp value. Sig. of $0.637>0.05$, and the width of the lettuce leaf blades obtained the calculated $F$ value $<F$ table which is $0.45<3.1$ at the $5 \%$ level. The highest treatment for leaf height $(4.53$ $\mathrm{cm} /$ month $)$ and leaf width $(1.77 \mathrm{~cm} /$ month) of lettuce was P1 treatment, while the highest number of leaves (3.24 pieces/month) was in the treatment P3.

Keywords: Hydroponics, Caffeinated Drink Dregs Waste, Lettuce Plant Growth (Lactuca sativa).

\section{PENDAHULUAN}

Indonesia merupakan Negara agraris yang mayoritas penduduknya bermata pencaharian sebagai petani. Pertanian merupakan sektor yang sangat penting bagi masyarakat Indonesia. Sektor pertanian sebagai sumber penghasilan bagi beberapa masyarakat, karena sebagian besar kawasan Indonesia merupakan lahan pertanian. Banyaknya lahan pertanian yang dipakai untuk pembangunan, sehingga lahan pertanian menjadi sempit untuk bercocok tanam bagi masyarakat, maka saat ini ada cara lain untuk memanfaatkan lahan yang sempit sebagai usaha mengembangkan hasil, yaitu dengan cara bercocok tanam secara media hidroponik. Hidroponik adalah budidaya pertanian tanpa menggunakan media tanah, sehingga hidroponik merupakan aktivitas pertanian yang dijalankan dengan menggunakan air sebagai medium utama untuk menggantikan tanah. Adapun jenis-jenis media tanam yang dapat dijadikan sebagai media hidroponik adalah: Rockwool, spons, batu apung, sabut kelapa, leca atau hidroton, arang sekam, zeolite, dll. Sehingga sistem bercocok tanam dengan cara media hidroponik dapat memanfaatkan lahan yang sempit. Jenis tanaman yang dapat ditanam dengan menggunakan media hidroponik adalah: bayam, kangkung, tomat, kentang, terong, cabai, paprika, sawi, wortel, seledri, pare, bawang merah, bawang putih, selada (Roidah, 2014: 43-44).

Selada merupakan salah satu sayuran yang banyak dibudidayakan dengan sistem hidroponik. Faktor pendukung utama dalam cocok tanam hidroponik pada pertumbuhan selada yaitu temperatur $25{ }^{\circ} \mathrm{C}$ sampai $28{ }^{\circ} \mathrm{C}$. selain itu faktor nutrisi merupakan faktor yang paling penting untuk pertumbuhan tanaman selada yakni nutrisi berupa $\mathrm{N}, \mathrm{P}$ dan K. ampas teh dan ampas kopi merupakan salah satu limbah yang mengandung kadar N,P,K yang cukup 
tinggi untuk pertumbuhan tanaman. Berdasarkan hasil penelitian widyati (2004), yang berjudul "pemanfaatan kompos ampas teh sebagai substitusi sumber nitrogen pada tanaman jagung manis (Zea mays saccharata)" menjelaskan bahwa dengan memberi pupuk campuran nintrogen tidak ada pengaruh pada tinggi tumbuhan jagung tersebut namun memberi perubahan yang cukup bagus terhadap pertumbuhan presentasi KAT.

Dari hasil penelitian ria adikasari (2012), bahwa dengan menggunakan Ampas teh dan ampas kopi pada tanaman cabe rawit (Capsicum frutesca L), menyatakan bahwa dengan memberikan limbah teh dan limbah kopi pada tumbuhan cabai dapat menghasilkan pertumbuhan yang sangat baik, dikarenakan pada limbah teh dan limbah kopi terdapat nutrisi yang berupa N,P,K yang berfungsi untuk meningkatkan pertumbuhan daun, batang dan juga akar. Namun belum ada yang teliti tentang pengaruh penambahan limbah tersebut pada tumbuhan selada (Lactuca sativa).

Berdasarkan latar belakang tersebut, peneliti tertarik untuk melakukan penelitian "Pengaruh Penambahan Limbah Ampas Minuman Berkafein Sebagai Media Tumbuh Hidroponik
Terhadap Pertumbuhan Tanaman

Selada (Lactuca sativa)".

Tujuan dari penelitian ini adalah, Untuk mengetahui pengaruh penambahan ampas teh dan ampas kopi terhadap pertumbuhan tanaman selada (Lactuca sativa) dan untuk mengetahui perlakuan manakah yang paling optimum terhadap pertumbuhan tanaman selada (Lactuca sativa) dengan media hidroponik.

\section{METODOLOGI PENRLITIAN}

Penelitian ini di laksanakan pada tanggal 22 Juni 2020 sampai tanggal 08 November 2020, di Desa Meurandeh Teungoh, Kec. Langsa Lama, Kota Langsa, Prov. Aceh.

\begin{abstract}
Alat dan Bahan
Alat yang digunakan pada penelitian ini yaitu: paralon, timbangan digital, kap agar-agar, paranet, nampan, sendok, penggaris, gunting, alat tulis, kamera, termometer, $\mathrm{pH}$ meter, bak penampung air, pompa sirkulasi.

Bahan yang digunakan yaitu: bibit selada, ampas teh, ampas kopi, air, rock wool, kain planel, kertas label.

Metode yang digunakan dalam penelitian ini adalah menggunakan metode eksperimen. Rancangan yang digunakan dalam penelitian ini yaitu Rancangan Acak Lengkap (RAL) yang terdiri dari 4
\end{abstract}


perlakuan dengan 6 kali ulangan. Adapun perlakuan pada penelitian ini adalah terdiri dari: P0: media tanam hidroponik (kontrol), P1: media tanam hidroponik + ampas teh (4 gr), P2: media tanam hidroponik + ampas kopi (4 gr), P3: media tanam hidroponik + ampas teh $(2$ gr $)+$ ampas kopi (2 gr). Kemudian dilakukan pengamatan selama 4 kali dalam waktu satu bulan pengamatan. Pengamatan dilakukan selama seminggu sekali. Adapun objek yang diamati berupa pertumbuhan tinggi tanaman, jumlah helaian daun dan lebar helaian daun tanaman selada (Juliati, 2018: 59).

\section{Analisis Data}

Hasil data penelitian yang diperoleh dianalisakan menggunakan (ANOVA) jika distribusi normal, dan jika Homogen menggunakan uji Nonparametrik yaitu uji Kruskal Wallis SPSS. Data yang didapatkan terlebih dahulu harus diuji dengan uji prasyarat yaitu, pengujian Normalitas dan pengujian Homogenitas.

\section{Hasil dan Pembahasan}

\section{Pertumbuhan Tinggi Tanaman Selada (Lactuca sativa)}

Mengukur tinggi tumbuhan selada dimulai dari umur 1minggu sampai umur selada 4 minggu dengan keselurugan pengukuran sebanyak 4 kali. Tinggi tumbuhan selada diukur mulai dari batang sampai ujung yang paling tinggi dengan menggunakan penggaris.

Hasil dari mengukur tinggi tumbuhan pada setiap perlakuan memiliki hasil yang berbeda-beda. Rata-rata tinggi tumbuhan selada yang paling optimum terdapat pada pemberian ampas teh (P1) 4,53 cm. selanjutnya diikuti pada perlakuan campuran ampas teh dan ampas kopi (P3), yaitu $3,91 \mathrm{~cm}$, kemudian pertumbuhan tinggi tanaman yang kontrol (P0), yaitu $3,62 \mathrm{~cm}$, dan yang terendah pada tinggi tumbuhan terdapat diperlakuan ampas kopi (P2), yaitu 2,83 cm. Berikut ini adalah grafik pertumbuhan tinggi tanaman selada pada setiap perlakuan.

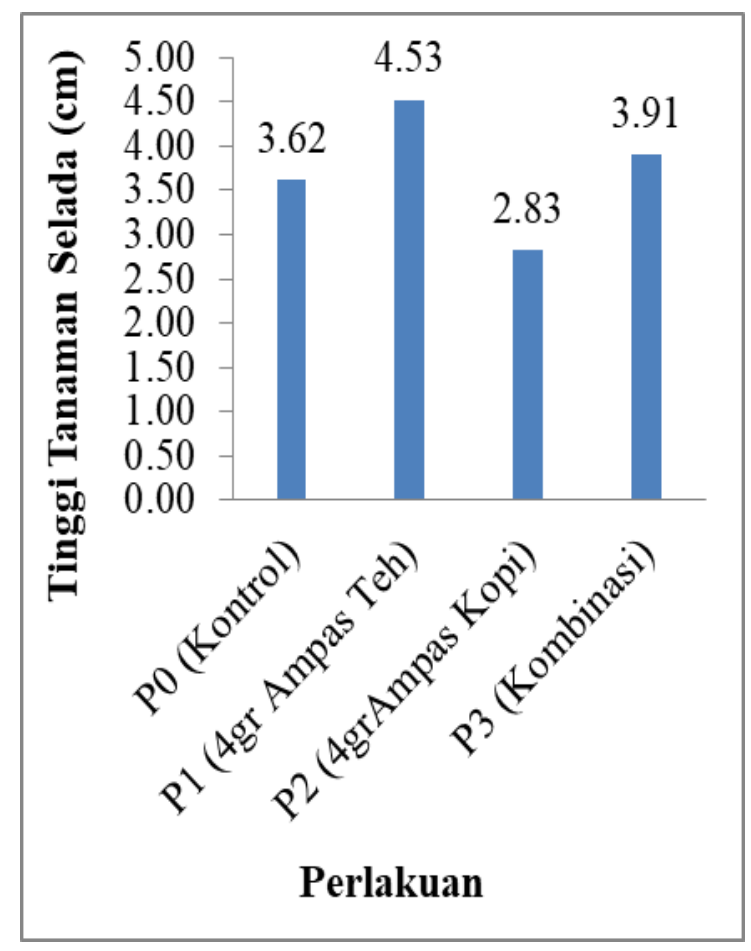


Gambar 4.1 Rata-Rata Tinggi Tanaman

Selada (Lactuca sativa).

Berdasarkan hasil analisis data menggunakan Uji Kruskal Wallis dapat dilihat pada tabel 1.1 sebagai berikut:

Kruskal-Wallis Test

Ranks

\begin{tabular}{l|lr|r}
\hline & Perlakuan & N & \multicolumn{1}{c}{ Rank } \\
\hline Tinggi & Kontrol & 4 & 6.75 \\
\cline { 2 - 4 } Tanaman & Ampas Teh & 4 & 8.63 \\
& $4 \mathrm{Gr}$ & & \\
\cline { 2 - 3 } & Ampas & 4 & 4.13 \\
& Kopi 4 Gr & & \\
\cline { 2 - 3 } & Total & 12 & \\
\hline
\end{tabular}

Test Statistics $^{\mathbf{a}, \mathbf{b}}$

Tinggi Tanaman

\begin{tabular}{lr}
\hline Chi-Square & 3.155 \\
\hline Df & 2 \\
\hline Asymp. & .206 \\
Sig. & \\
\hline a. Kruskal Wallis Test & \\
b. Grouping Variable: & \\
Perlakuan &
\end{tabular}

Dari tabel diatas dapat dilihat bahwa data yang diperoleh pada tinggi tanaman selada (Lactuca sativa) dengan menggunakan Uji Kruskal Wallis, tidak ada perbedaan yang nyata. Hal ini ditunjukan bahwa nilai Asymp. Sig. sebesar 0,206 >0,05. Dengan demikian dapat ditarik kesimpulan bahwa tidak ada pengaruh penambahan limah teh dan limbah kopi sebagai media tumbuh hidroponik terhadap pertumbuhan tanaman selada (lactuca sativa).

\section{Jumlah Helaian Daun Selada (lactuca sativa)}

Berdasarkan pengamatan terhadap jumlah helaian daun tanaman selada dilakukan dengan cara menghitung jumlah daun yang telah membuka hingga satu bulan. Pertumbuhan jumlah helaian daun yang diperoleh merupakan perhitungan selisih dari jumlah helaian daun akhir dengan jumlah awal helaian daun. Ratarata pertumbuhan jumlah helaian daun tanaman selada yang paling banyak adalah pada perlakuan pemberian $2 \mathrm{gr}$ ampas teh+2gr ampas kopi (P3) yaitu 3,24 helai daun, disusul dengan perlakuan 4 gr ampas teh (P1) yaitu 3,20 helai daun, kemudian diikuti lagi pada perlakuan kontrol (P0) yaitu 2,87 helai daun, sedangkan yang paling sedikit pertumbuhan jumlah helaian daun adalah pada perlakuan 4 gr ampas kopi (P2) yaitu 2,70 helai daun. Dapat dilihat grafik jumlah helaian daun tumbuhan selada pada setiap perlakuan. 


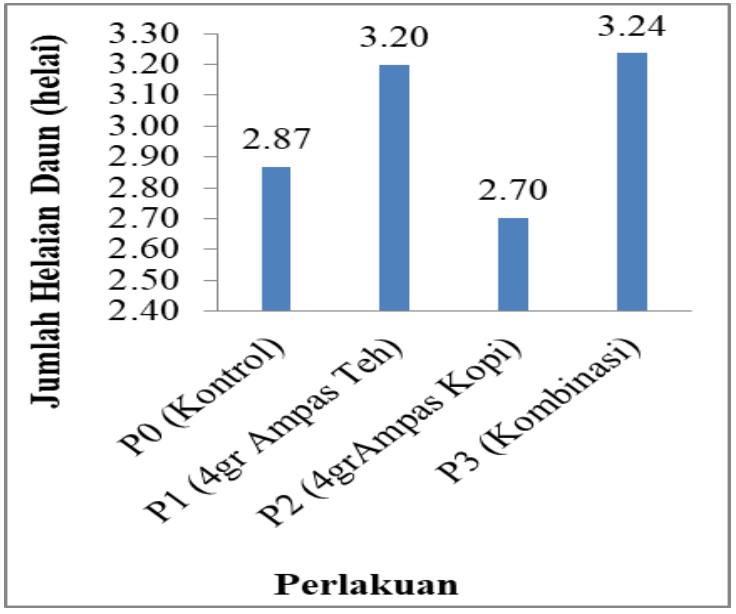

Gambar 4.2. rata-rata jumlah helaian daun tanaman selada (Lactuca sativa).

Berdasarkan hasil analisis data menggunakan Uji Kruskal Wallis dapat dilihat pada tabel 1.2 sebagai berikut:

\section{Kruskal-Wallis Test}

\section{Ranks}

\begin{tabular}{|c|c|c|c|}
\hline & Perlakuan & $\mathbf{N}$ & $\begin{array}{l}\text { Mean } \\
\text { Rank }\end{array}$ \\
\hline \multirow{4}{*}{$\begin{array}{l}\text { Jumlah } \\
\text { Daun }\end{array}$} & KONTROL & 4 & 5.88 \\
\hline & $\begin{array}{l}\text { Ampas Teh } 4 \\
\text { Gr }\end{array}$ & 4 & 7.88 \\
\hline & $\begin{array}{l}\text { Ampas Kopi } \\
4 \mathrm{Gr}\end{array}$ & 4 & 5.75 \\
\hline & Total & 12 & \\
\hline
\end{tabular}

Test Statistics ${ }^{\text {a,b }}$

\begin{tabular}{lr} 
& Jumlah Daun \\
\hline Chi-Square & .903 \\
\hline Df & 2 \\
\hline Asymp. & .637 \\
Sig. & \\
\hline
\end{tabular}

helaian daun tanaman selada (Lactuca sativa) dengan menggunakan Uji Kruskal Wallis, tidak ada perbedaan yang nyata. Hal ini ditunjukan bahwa nilai Asymp. Sig. sebesar 0,637>0,05. Dengan demikian dapat ditarik kesimpulan bahwa tidak ada pengaruh penambahan limah teh dan limbah kopi sebagai media tumbuh hidroponik terhadap pertumbuhan tanaman selada (lactuca sativa).

\section{Lebar Daun Tanaman Selada (lactuca sativa)}

Pada daun tanaman selada setiap perlakuan memiliki lebar daun yang berbeda-beda. Lebar daun tanaman selada yang paling optimal pada penambahan limbah teh dan kopi ini yaitu terdiri dari perlakuan $(\mathrm{P} 1)$ dengan lebar daun $1,77 \mathrm{~cm}$, dan disusul dengan perlakuan (P0) yaitu $1,34 \mathrm{~cm}$, selanjutnya diikuti pada perlakuan (P3) yaitu $1,11 \mathrm{~cm}$, sedangkan lebar daun yang terendah adalah pada perlakuan (P2) yaitu $0,65 \mathrm{~cm}$. Dapat dilihat grafik jumlah helaian daun tumbuhan selada pada setiap perlakuan.

Dari tabel diatas dapat dilihat bahwa data yang diperoleh pada jumlah 


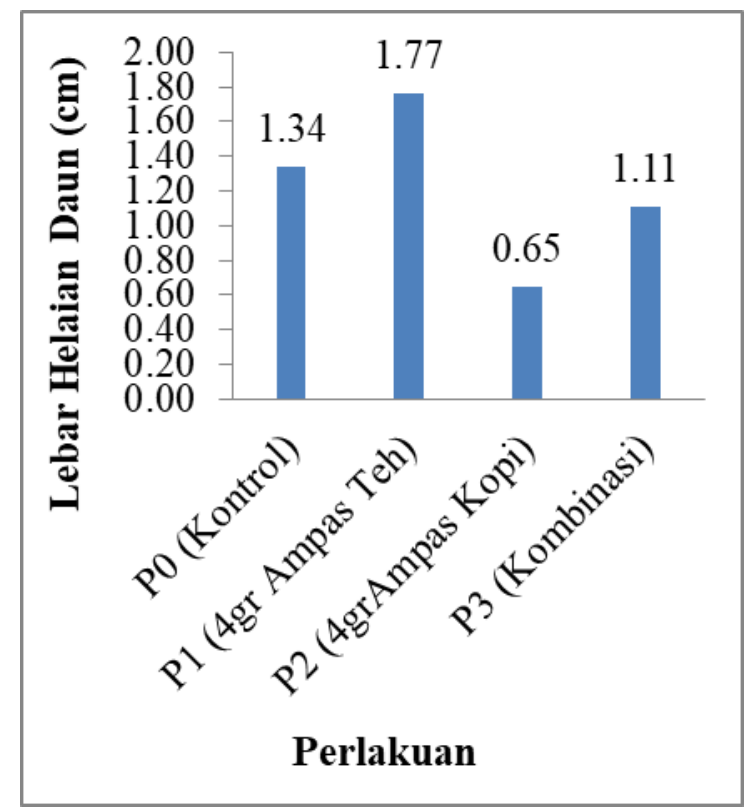

Gambar 4.3. rata-rata lebar daun tanaman selada (Lactuca sativa).

Berdasarkan hasil analisis data menggunakan ANOVA dipeoleh data lebar daun tanaman selada (lactuca sativa) tidak memiliki pengaruh yang nyata. Hal ini ditunjukan dengan data analisis bahawa $\mathrm{F}$ hitung $<\mathrm{F}$ tabel yaitu $0,45<3,1$ pada taraf $5 \%$ dan $0,45<4,94$ pada taraf $1 \%$, maka tidak dapat dilakukan uji lanjut.

\section{PEMBAHASAN}

Berdasarkan hasil penelitian dan analisis data dilakukan oleh peneliti menunjukkan bahwa pemberian limbah teh dan kopi tidak berpengaruh nyata semua parameter yang ada. Namun memiliki perbedaan pada setiap rata-rata perlakuan terhadap pertumbuhan tanaman selada (Lactuca sativa) dengan diameter tinggi tumbuhan $(4,53 \mathrm{~cm})$, jumlah helai daun
(3,24 helaian), dan lebar daun $(1,77 \mathrm{~cm})$ yang akan dibahas dibawah ini:

Pertumbuhan Tinggi Tanaman dan lebar daun selada (Lactuca sativa), pada penambahan limbah teh dan kopi memberi pengaruh baik pada tanaman selada (Lactuca sativa). Pada hasil tinggi dan lebar daun selada adalah terdapat pada perlakuan (P1) dengan pemberian limbah teh sebanyak 4 gr. Hal ini diduga karna pada ampas teh terdapat barbagai macam unsur hara yaitu nitrogen $(\mathrm{N})$, fosfor $(\mathrm{P})$, kalium $(\mathrm{K})$, besi $(\mathrm{Fe})$, seng $(\mathrm{Zn})$, tembaga $(\mathrm{Cu})$, kalsium $(\mathrm{Ca})$, dan magnesium $(\mathrm{Mg})$. dimana unsur hara tersebut sangat dibutuhkan oleh tumbuhan terutama pada tanaman selada (Lactuca sativa), semua unsur-unsur tersebut termasuk unsur hara makro dan mikro (Team Penulis PS, 1993: 30). Nitrogen berguna dalam pengaktifan hormon pertumbuhan akar dan batang, karsium berfungsi untuk membentuk stabilitas dinding sel dan pemeliharaan struktur, magnesium dan seng juga sebagai komponen klorofil dan mengaktifkan enzim, tembaga berguna dalam biosintesis lignin. Hal inilah membuat pertumbuhan selada lebih cepat tumbuh pada perlakuan pemberian ampas teh.

Menurut Sumiarsih (1992: 36), bahwa penambahan limbah teh dan kopi yang telah ditambahkan pada tanaman selada telah diserap oleh tumbuhan selada 
(Lactuca sativa) untuk membentukkan organ-organ pada tumbuhan. Namun lain halnya pada pemberian 4gr limbah kopi. Penyebab mengapa pada pemberian 4gr ampas kopi mengakibatkan pertumbuhan tinggi tanaman dan lebar daun renda, dikarnakan unsur hara yang terdapat pada ampas kopi tidak mencukupi. Yang kita ketahui unsur hara $\mathrm{N}, \mathrm{P}$ dan $\mathrm{K}$ yang diperlukan pada tanaman selada masing masing sebanyak 20\%. Sedangkan unsur hara yang diperoleh pada ampas kopi adalah N (1,69\%), P (0,18\%), K (2,49\%) (Siahaan, Retno, 2019: 123).

Yang kita ketahui semua tanaman selain memerlukan air, tumbuhan juga memerlukan nutrisi makro dan mikro yang cukup sebagai sumber makanan. Dimana makro seperti (N, P, Ca, Mg dan S) dan mikro seperti (Fe, Mn, Cu, Zn, B dan Mo) semua unsur hara makro dan mikro adalah nutrisi yang sangat diperlukan semua jenis tumbuhan, maka apabila kelebihan atau kekurangan salah satu unsur hara pada tanaman maka tanaman akan mengakibatkan stres (Beyamin lakitan, 2007: 53).

Sedangkan pada perhitungan jumlah helaian daun pada penelitian ini yang paling banyak terdapat pada perlakuan penambahan $2 \mathrm{gr}$ ampas teh + 2gr ampas kopi (P3), hal ini diduga karena pada combinasi ampas teh dan ampas kopi terdapat unsur hara yang dapat mencukupi peningkat pertumbuhan daun yang baru. Unsur hara yang terdapat pada ampas kopi dan ampas teh adalah N,P,K, kalsium (Ca), tembaga $(\mathrm{Cu})$, seng $(\mathrm{Zn})$, magnesium $(\mathrm{Mg})$ sehingga dapat membantu pertumbuhan tanaman (Rodiana, 2007). Hara yang sagat dibutuhkan pada pertumbuhan daun baru yaitu seng $(\mathrm{Zn})$, magnesium $(\mathrm{Mg})$, nitrogen $(\mathrm{N})$, dimana seng $(\mathrm{Zn})$ berfungsi dalam pembentukan klorofil, hormon pertumbuhan, magnesium $(\mathrm{Mg})$ berperan pembentukan zat hijau daun, dan nitrogen (N) berfungsi merangsang pertumbuhan akar, batang dan daun, dan juga berperan dalam pembentukan zat hijau daun (klorofil) yang sangat penting untuk melakukan proses fotosintesis. Apabila pada pertumbuhan selada kekurangan dan kelebihan salah satu unsur hara terutama pada unsur nitrogen $(\mathrm{N})$, maka tanaman akan mengakibatkan klorosis, daun kecil, berwarna merah tua, pembentukan akar yang tidak normal.

Sedangkan hasil perhitungan jumlah daun pada penelitian ini yang paling segikit terdapat pada perlakuan pemberian 4gr ampas kopi (P2), hal ini diduga karena kekurangan unsur hara nitrogen $(\mathrm{N})$, dan kekurangan seng $(\mathrm{Zn})$, dan magnesium (Mg) pada ampas kopi, sehingga terhambatnya pembentukan daun yang baru. Pada pertumbuhan daun 
termasuk jumlah dan lebar helaian daun tidak hanya dipengaruhi oleh unsur hara saja melainkan dipengaruhi juga oleh faktor lingkungan salah satunya itu adalah pH. Diketahui bahwa pertumbuhan yang baik untuk tanaman yaitu pada $\mathrm{pH}$ 6,5 sampai 7. Menurut lusito dalam adikasari (2012: 03), pH pada limbah kopi sedikit asam, berkisar 6,2 pada skala $\mathrm{pH}$. Apa bila pH kurang dari 6 maka akan mengurangi kandungan unsur hara yang dapat menyebabkan tanaman akan mudah rebah dan pertumbuhan menjadi terhambat, sementara pada $\mathrm{pH}$ diatas 7 maka tanaman akan mengalami klorosis.

\section{KESIMPILAN}

Berdasaran penelitian yang telah dilakukan maka dapat disimpulkan bahwa

1. Tidak terdapat pengaruh yang signifikan ataupun yang sangat signifikan pada penambahan ampas teh dan ampas kopi terhadap pertumbuhan tanaman selada (Lactuca sativa) dengan menggunakan media tanam hidroponik.

2. Perlakuan yang paling optimum untuk pertumbuhan tinggi tanaman dan lebar daun terdapat pada perlakuan P1 (ampas teh $4 \mathrm{gr}$ ). Sedangkan yang paling optimum untuk jumlah helaian daun terdapat pada perlakuan P3 (campuran).

\section{DAFTAR PUSTAKA}

Adikasari, R. 2012. Pemanfaatan Ampas Teh Dan Ampas Kopi Sebagai Penambah Nutrisi Pada Pertumbuhan Tanaman Tomat (Solanum lycopersicum) Dengan Media Hidroponik (Skripsi). Surakarta: Universitas Muhammadiyah Surakarta.

Beyamin lakitan. 2007. Dasar-dasar Fisiologi Tumbuhan. Jakarta: PT. Raja Grapindo Persada.

Juliati, 2018. "Pengaruh Pemberian Ampas Teh Dan Kopi Terhadap Pertumbuhan Tanaman Tomot (Lycopersicus esculentum Mill) Dengan Media Hidroponik" Skripsi. Fakultas Ilmu Tarbiyah Dan Keguruan. Universitas Islam Negeri Mataram.

Roidah, I.S, 2014. "Pemanfaatan Lahan Dengan Menggunakan Sistem Hidroponik". Jurnal Universitas Tulungagung Bonorowo, Vol.1 No.2.

Widyati, Slamet, 2004. "Pemanfaatan Kompos Ampas Teh Sebagai Substitusi Sumber Nitrogen Pada Tanaman Jagung (Zea mays seccharata)" Artikel Ilmiah 
Saparinto, C. 2013. Grow Your Own Vegetables-Panduan Praktis Menanam 14 Sayuran Komsumsi Populer Di Pekarangan. Yogyakarta: Penebar Swadaya.

Siahaan. W, Retno S. 2019. "Pengaruh Aplikasi Kompos Ampas Kopi Terhadap Perubahan Sifat Kimia Andisol Ngabab, Kabupaten Malang". Jurnal Tanah Dan Sumberdaya Lahan. Vol. 6 No.1

Sumiarsih, Emmy, 1992. Hidroponik Tanaman Hias. Jakarta: Penebar Swadaya.

Team Penulis PS.1993. Pengelolaan dan Pengolahan Teh. Penebar Swadaya. Jakarta. 